\title{
Cardiac side population cells exhibit endothelial differentiation potential
}

\author{
Jihyun Yoon ${ }^{1 *}$, Seung-Cheol Choi ${ }^{1 *}$, \\ Chi-Yeon Park ${ }^{1}$, Wan-Joo Shim ${ }^{1}$ and Do-Sun Lim ${ }^{1,2}$ \\ ${ }^{1}$ Department of Cardiology \\ College of Medicine, Korea University \\ Seoul 136-705, Korea \\ ${ }^{2}$ Corresponding author: Tel, 82-2-920-5445; \\ Fax, 82-2-927-1478; E-mail, dsImd@ kumc.or.kr \\ *These authors contributed equally to this work.
}

Accepted 10 September 2007

Abbreviations: $\mathrm{AH}$, adult heart; $\mathrm{BM}$, bone marrow; LDPI, laser Doppler perfusion image; Sca1, stem cell antigen1; SDF1, stromal cell derived factor1; SP, side population

\begin{abstract}
Recent studies have shown that side population (SP) cells, isolated from adult myocardium, represent a distinct cardiac progenitor cell population that exhibits functional cardiomyogenic differentiation. However, information on the intrinsic characteristics and endothelial potential, of cardiac SP cells, is limited. The present study was designed to investigate whether cardiac SP cells exhibit endothelial differentiation potential. The cardiac SP cells more highly expressed the early cardiac transcription factors as well as endothelial cell markers compared to the bone marrow-SP cells. After treatment with VEGF, for 28 days, cardiac SP cells were able to differentiate into endothelial cells expressing von Willebrand factor as determined by immunocytochemistry. Furthermore, expression of endothelial cell markers increased several-fold in VEGF-treated cardiac SP cells compared to the control group when assessed by real-time PCR. We also confirmed that cardiac SP cells provided a significantly augmented ratio of ischemic/normal blood flow, in the cardiac SP cell-transplanted group compared with saline-treated controls on postoperative days $7,14,21$ and 28 , in a murine model. These results show that cardiac SP cells may contribute to regeneration of injured heart tissues partly by transdifferentiation into angiogenic lineages.
\end{abstract}

Keywords: bone marrow; cell differentiation; cell transplantation; heart; infarction; stem cells

\section{Introduction}

Until recently, the adult mammalian heart was considered to be a terminally differentiated organ, and therefore a massive loss of cardiomyocytes, as a consequence of myocardial infarction, was thought to be an irreversible process subsequently resulting in heart failure. However, recent studies have suggested the possibility of cardiac progenitor/stem cells in the adult heart. The presence of immature cycling cardiomyocytes, in human hearts, can proliferate under certain pathologic conditions (Beltrami et al., 2001). Recently, Beltrami et al. (2003) reported that c-kit ${ }^{+}$cardiac stem cells are multi-potent and support myocardial regeneration. Stem cell antigen (Sca1) ${ }^{+}$cells, from adult myocardium, have been shown to differentiate into beating cardiomyocytes (Oh et al., 2003; Matsuura et al., 2004). Postnatal is ${ }^{+}$cardioblasts were shown to enter fully differentiated cardiomyogenic lineages (Laugwitz et al., 2005).

Side population (SP) cells, which are characterized by their intrinsic capacity to efflux Hoechst dye, were first isolated from bone marrow (BM) (Asakura and Rudnicki, 2002). SP cells have also been isolated from other adult tissues such as: brain, kidney, liver, lung, mammary gland, skin, small intestine, spleen, testis and heart (Asakura and Rudnicki, 2002; Hierlihy et al., 2002; Welm et al., 2002; Lassalle et al., 2004; Martin et al., 2004; Pfister et al., 2005; Yano et al., 2005). Recently, cardiac SP cells have been shown to exhibit functional cardiomyogenic differentiation (Pfister et al., 2005) demonstrating that SP cells represent a distinct cardiac progenitor cell population. However, the characteristics and endothelial potential of cardiac SP cells have not been fully described. In this study, we have demonstrated that cardiac SP cells expressed cardiac transcription factors as well as endothelial cell markers by comparing them with BM-SP cells, differentiated into endothelial cells in vitro. Furthermore, we showed that cardiac SP cells increased the restoration of blood flow when injected into an ischemic murine hindlimb. 


\section{Materials and Methods}

\section{Isolation and characterization of side population cells}

All animal procedures were performed in accordance with the guidelines of the Institutional Animal Care and Use Committee, College of Medicine, Korea University (Seoul, Korea). Adult Balb/C mice (6-8 wks) were used for isolation of SP cells from the bone marrow and heart. The aorta and vessels were removed from the heart tissue. The heart tissue was minced and digested for $30 \mathrm{~min}$ at $37^{\circ} \mathrm{C}$ in $0.5 \mathrm{mg} / \mathrm{ml}$ Type II collagenase (Worthington, Lakewood, $\mathrm{NJ}$ ). Bone marrow cells were extracted after flushing the femurs and tibias of Balb/C mice of 6-8 weeks of age with HBSS (Invitrogen, Carlsbad, CA) containing 2\% FBS (Gibco, Grand Island, NY). Analysis and sorting of BM- and cardiac SP cells were performed as described previously (Laugwitz et al., 2005). For staining cell specific surface markers, the SP cells were incubated on ice for $15 \mathrm{~min}$ with PE-conjugated anti-Sca1 antibody (BD Biosciences, San Jose, $\mathrm{CA}$ ), with FITC-conjugated anti-CD45 antibody (BD Biosciences), and FITC-conjugated anti-c-kit antibody (BD Biosciences). Analysis and cell sorting were performed on a FACS Vantage SE flow sorter (BD Biosciences).

\section{RT-PCR and real-time PCR}

Total RNAs were extracted from adult heart (AH)and BM-SP cells using the RNAqueous kit (Ambion, Austin, TX). RT-PCR reactions were carried out as described previously (Choi et al., 2004). The PCR reaction was carried out for 27 cycles for GAPDH, for 35 cycles for GATA4, atrial natriuretic factor (ANF) and Nkx2.5 primers. Real-time $\mathrm{PCR}$ was performed using an $\mathrm{iQ}^{\mathrm{TM}}$ Cycler (Bio-Rad, Hercules, CA); each reaction contained $25 \mu \mathrm{l}$ of the $\mathrm{iQ}^{\mathrm{TM}}$ SYBER Green Supermix (Bio-Rad), $3 \mu$ l forward primer $(5 \mu \mathrm{M}), 3$ $\mu \mathrm{l}$ reverse primer $(5 \mu \mathrm{M}), 5 \mu \mathrm{l}$ of a 1:20 dilution of a cDNA, and $14 \mu \mathrm{l} \mathrm{H}_{2} \mathrm{O}$. PCR conditions: denaturation step $\left(95^{\circ} \mathrm{C}\right.$ for $\left.3 \mathrm{~min}\right)$, amplification and quantification program repeated 45 times $\left(94^{\circ} \mathrm{C}\right.$ for $15 \mathrm{~s}, 60^{\circ} \mathrm{C}$ for $30 \mathrm{~s}$, and $72^{\circ} \mathrm{C}$ for $\left.30 \mathrm{~s}\right)$, and melting curve program $\left(55-95^{\circ} \mathrm{C}\right.$ with a heating rate of $0.05^{\circ} \mathrm{C} / \mathrm{s}$ ). The primers used for PCR were as follows: ATP-binding cassette transporter $G 2$ (ABCG2) (CCATAGCCACAGGCCAAAGT, GGGCCACATGATTCTTCCAC, 327 bp); Angiopoietin1 (GGGGGAGGTTGGACAGTAAT, CGAACCACCAACCTCCTGTT, 388 bp); Angiopoietin2 (GTCCATGAAGGAGCAGAAGG, GCCTTGATCTCCTCTGTGGA, 312 bp); ANF (TTGGCTTCCAGGCCAT-
AATT, AAGAGGGCAGATCTATCGGA, 282 bp); CD31 (AGAGACGGTCTTGTCGCAGT, TACTGGGCTTCGAGAGCATT, 152 bp); CXCR4 (GGCTGTAGAGCCAGTGTTGC, GTAGAGGTTGACAGTGTAGA, 390 bp); FIk1 (GGCGGTGGTGACAGTATCTT, GTCACTGACAGAGGCGATGA, 162 bp); FIt1 (CGGAAGCTCTGATGATGTGA, TATCTTCATGGAGGCCTTGG, 199 bp); GAPDH (TTCACCACCATGGAGAAGGC, GGCATGGACTGTGGTCATGA, 236 bp); GATA4 (CTGTCATCTCACTATGGGCA, CCAAGTCCGAGCAGGAATTT, 259 bp); Nkx2.5 (AGCAACTTCGTGAACTTTG, CCGGTCCTAGTGTGGA, $345 \mathrm{bp}$ ); stromal cell derived factor1 (SDF1; CGTGAGGCCAGGGAAGAGT, TGATGAGCATGGTGGTTGA, 69 bp); Tie1 (CAGGCACAGCAGGTTGTAGA, GTGCCACCATTTTGACACTG); Tie2 (AAGCATGCCCATCTGGTTAC, GCCTGCCTTCTTTCTCACAC, 138 bp); VEGF (ACCCTGGTGGACATCTTCCA, TCATCGTTACAGCAGCCTGC, $101 \mathrm{bp}$ ). The relative gene expression levels were quantified based on the threshold cycle $(\mathrm{Ct})$, and normalized to the reference gene GAPDH.

\section{Colony forming unit assay}

Colony forming unit (CFU) assays were performed by plating $\mathrm{AH}$ - or BM-SP cells $\left(4 \times 10^{3} \mathrm{cells} / \mathrm{ml}\right)$ in Methocult M3434 methylcellulose medium (Stemcell Technologies, Vancouver, BC, Canada) into 35-mm culture dishes according to the instructions of the manufacturer. CFUs were scored (colony > 25 cells) 14 days after plating and expressed as a percentage of control.

\section{Endothelial differentiation}

To induce differentiation into endothelial cells, AH-SP cells were plated at $1 \times 10^{4}$ cells/well on fibronectin-coated chamber slides (Nalge Nunc International, Naperville, IL), in $60 \%$ low-glucose DMEM (Invitrogen) and 40\% MCDB-201 (Sigma, St. Louis, MO), supplemented with $1 \times$ insulin-transferrin-selenium, $1 \times$ linoleic acid-BSA, $10^{-8} \mathrm{M}$ dexamethasone, $10^{-4} \mathrm{M}$ ascorbic acid 2-phosphate (all from Sigma), $100 \mathrm{U}$ penicillin, and 1,000 U streptomycin (Invitrogen), plus $20 \mathrm{ng} / \mathrm{ml}$ VEGF (R \& D Systems, Minneapolis, MN) and 2\% FBS. For immunohistochemistry, AH-SP cells were fixed for 15 min using 4\% paraformaldehyde, permeabilized with $0.1 \%$ Triton $X-100$ in PBS for $5 \mathrm{~min}$, and blocked with $5 \%$ normal goat serum in PBS + $0.05 \%$ Tween 20 for $1 \mathrm{~h}$. The cells were incubated for $1 \mathrm{~h}$ in CD31 (BD Biosciences) and von Willebrand Factor (VWF) antibodeis (Dako, Carpinteria, CA) and Alexa 488-conjugated secon- 
dary antibodies (Molecular probes, Eugene, OR). Cell nuclei were visualized with $4 \mu \mathrm{g} / \mathrm{ml} 4^{\prime}$, 6-diamidino-2-phenylindole (DAPI, Sigma). Cells were then washed 3 times with PBS $+0.05 \%$ Tween 20 and mounted under cover glass with fluorescent mounting medium (Dako). The fluorescence images were collected with the TE-FM EpiFluorescence system attached to an Olympus Inverted Microscope (Olympus, Tokyo, Japan).

\section{Laser Doppler blood perfusion analysis}

A murine model of surgically induced hindlimb ischemia was employed for determining the impact of cardiac SP cells on therapeutic regeneration. Balb/C (6-8 wk-old) mice were used for the experiments. Animals underwent left femoral artery ligation. Mice were anesthetized with a mixture of $40 \mathrm{mg} / \mathrm{kg}$ of ketamine and $100 \mathrm{mg} / \mathrm{kg}$ of xylazine. A skin incision was performed on the medial aspect of the left thigh. After careful dissection of the vein and nerve, the femoral artery was ligated immediately distal to the inguinal ligament and proximal to the popliteal bifurcation site. One day after the operative excision of the left femoral artery and vein, Balb/C mice $(n=30)$, received an intramuscular injection of $1 \sim 2 \times 10^{5}$ cardiac SP cells. The control group was injected with media $(n$ $=30$ ). For the purpose of cardiac-SP tracking, cells were marked with the fluorescent carbocyanine Dil dye (Molecular Probes, Eugene, OR). Before cardiac-SP isolation, cells in suspension were washed with PBS and incubated with $2.5 \mu \mathrm{g} / \mathrm{ml}$ of Dil in PBS for $5 \mathrm{~min}$ at $37^{\circ} \mathrm{C}$ and $15 \mathrm{~min}$ at $4^{\circ} \mathrm{C}$. After two washing steps in PBS, the cells were resuspended in HBSS containing $2 \%$ FBS. The cardiac-SP cells were then isolated by flow cytometry. The ischemic/normal hindlimb blood perfusion ratio was measured using a laser Doppler perfusion image (LDPI) analyzer (Moor Instruments, Devon, UK). The changes were displayed as a color-coded image representing blood flow. Low to no flow was displayed as dark blue, whereas high flow was displayed as red to white. Before initiating laser scanning, animals were placed on a heating plate kept at $37^{\circ} \mathrm{C}$ to minimize data variations due to body temperature. At predetermined time points (before and on cell transplantation days $7,14,21$ and 28), we performed two consecutive scans over the same region of interest (leg and feet) in each animal and found essentially no difference between the two scans. After scanning them twice, the stored images were subjected to computer-assisted quantification of blood flow, and the average flow of the ischemic and non-ischemic feet were calculated. To mini- mize data variables due to ambient light and temperature, the LDPI index was expressed as the ratio of left (ischemic) to right (normal) limb blood flow.

\section{Histological analysis}

At 4 weeks after cell transplantation, the lower hindlimb musculatures were harvested. The tissue specimens were embedded with OCT compound (Tissue-Tek, Sakura Finetechnical Co, Tokyo, Japan) and frozen sections were cut at $10 \mu \mathrm{m}$ thickness on a cryostat (Microm, Heidelberg, Germany). Tissue sections were immunostained with anti-vWF antibody or anti- $\alpha$-smooth muscle actin antibody ( $\alpha$-SMA, Sigma), followed by incubation with FITC-conjugated IgG antibody (Sigma). At 4 weeks after cell transplantation, the lower hindlimb musculatures ( $n=10$ per group) were harvested. Total RNA was isolated using Trizol reagent (Invitrogen). RT reaction was performed as described above. The primers used for real-time PCR were as follows: Flk1 (GGCGGTGGTGACAGTATCTT, GTCACTGACAGAGGCGATGA, 162 bp); vWF (AGTCCCCTGTCTCACCGTAG, TAGCACACTCCAGCCCTTG, 106 bp).

\section{Statistical analysis}

All values are expressed as mean \pm SEM. A value of $P<0.05$ was considered to be statistically significant. Statistical analysis was performed using a Student's $t$ test to examine the significance of differences between the two groups.

\section{Results}

\section{Isolation and characterization of adult heart- and bone marrow-SP cells}

SP cells were isolated from the adult heart and bone marrow based on the ability of the cell population to efflux Hoechst 33342 using dualwavelength flow cytometry. $\mathrm{AH}-$ and $\mathrm{BM}-\mathrm{SP}$ cells showed a typical SP staining pattern, representing $0.29 \pm 0.13 \%$ (mean \pm SEM) of adult heart cells and $0.14 \pm 0.03 \%$ of bone marrow cells, respectively (Figure $1 \mathrm{~A}$ ). SP formation was blocked by incubating the cells with the antagonist $50 \mu \mathrm{M}$ verapamil, confirming the $\mathrm{SP}$ phenotype (Figure 1A).

To investigate the surface marker expression of AH-SP cells compared with BM-SP cells, $\mathrm{AH}$ - and BM-SP cells $(n=7)$ were labeled with antibodies to stem cell markers (Sca1 and c-kit) and the hematopoietic marker (CD45). In AH-SP cells, 
A

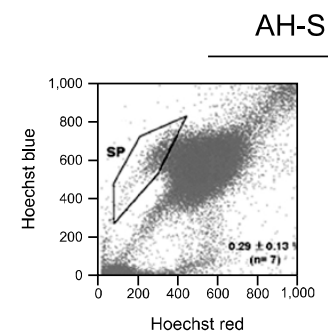

AH-SP cells

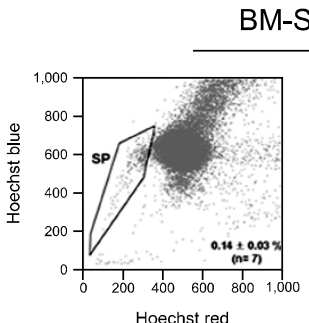

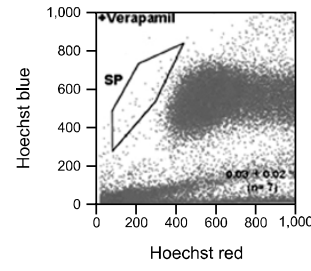

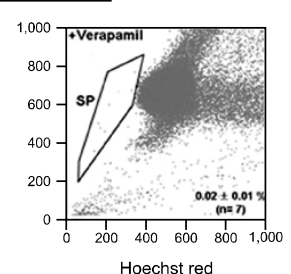

B

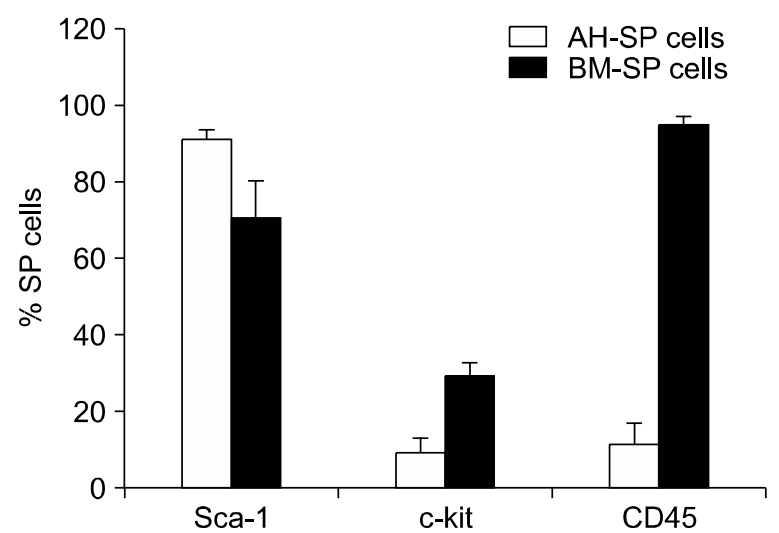

Figure 1. Isolation and characterization of adult heart- and bone marrow-SP cells using flow cytometry. (A) SP cell populations were isolated from adult heart or bone marrow using a dual-wavelength fluorescence-activated cell sorter and Hoechst 33342 dye. Treatment with the ATP-binding cassette transporter inhibitor, verapamil abrogated the ability of the SP cells to efflux the Hoechst 33342 dye. (B) AH- and BM-SP cells were immunophenotyped by analyzing stem cell markers (Sca1 and c-kit) or a hematopoietic marker (CD45) using flow cytometry. Values (mean \pm SEM) are based on seven separate experiments. AH, adult heart; BM, bone marrow; SP, side population.

Sca1, c-kit and CD45 were each expressed on a proportion of SP cells $(91.99 \pm 1.73 \%, 9.6 \pm$ $4.05 \%$, and $11.67 \pm 14.83 \%$, Figure 1B). Whereas for the BM-SP cells, Sca1, c-kit and CD45 were each expressed on a proportion of SP cells $(70.8$ $\pm 10.36 \%, 29.24 \pm 3.54 \%$, and $95.23 \pm 2.01 \%$, Figure 1B).

\section{Adult heart-SP cells intrinsically express early cardiac transcription factors and endothelial cell markers}

We examined expression of marker genes, for different cell lineage commitment, to compare the properties of SP cells, derived from adult heart and bone marrow. RT-PCR showed that expression of early cardiac transcription factors such as GATA4, ANF and Nkx2.5 was higher in freshly isolated AH-SP cells compared to the BM-SP cells (Figure $2 A)$. This result suggests that cardiac SP cells have intrinsic characteristics for differentiating into cardiomyocytes. By contrast, expression of these cardiac transcription markers was undetectable in the BM-SP cells.

To determine the expression of genes, specific for stem cell mobilization, AH- and BM-SP cells were studied using real-time PCR analysis (Figure 2B). A key stem cell homing factor, SDF1 mRNA expression was $\sim 3.8$-fold higher in AH-SP cells than in the BM-SP cells. By contrast, mRNA expression of CXCR4, the receptor for SDF1 which plays a role in the homing of hematopoietic stem cells, was $\sim 3.7$-fold higher in BM-SP cells than in the $\mathrm{AH}-\mathrm{SP}$ cells (Figure 2B). Expression of the ABCG2 gene, which has been implicated in the SP phenotype, was $\sim 5.2$-fold higher in AH-SP cells than the BM-SP cells (Figure 2B).

We also examined the expression of molecules associated with endothelial cell function or angiogenesis in $\mathrm{AH}$ - and BM-SP cells. Unexpectedly, expression of endothelial cell markers was higher in AH-SP cells than BM-SP cells. Expression of CD31, VEGF receptor-1 (VEGFR1, FIt1) and VEGFR-2 (Flk1), Tie1, and Tie2 mRNA were $\sim 24.9, \sim 430, \sim 860, \sim 9.9$ and $\sim 188$-fold higher in AH-SP cells than in the BM-SP cells, respectively (Figure 2C). These results demonstrate that AH-SP cells have inherent stem cell potential for differentiation into endothelial cells compared to the BM-SP cells.

\section{Adult heart-SP cells represent hematopoietic colony forming activity}

To elucidate whether SP cells could differentiate into hematopoietic cells in vitro, SP cells were fractionated by flow cytometry into SP populations. The SP cells derived from the heart had a lower frequency of hematopoietic colonies compared with the bone marrow colonies (Figure 3). This result suggests that the AH-SP cells are capable of proliferation and differentiation to form hematopoie- 


\section{A}

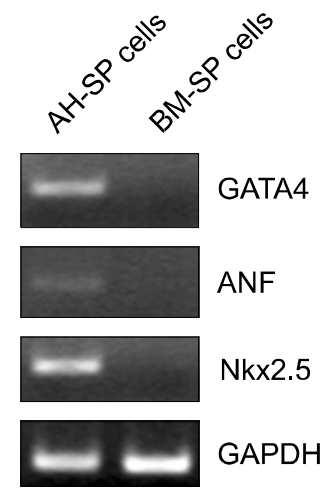

B

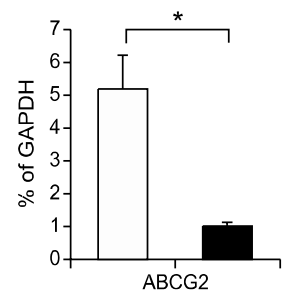

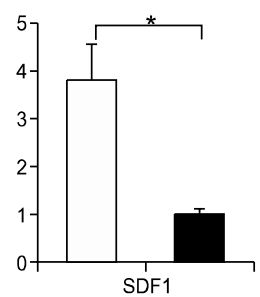

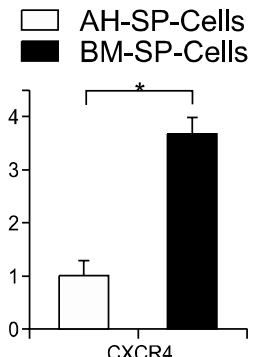

\section{C}
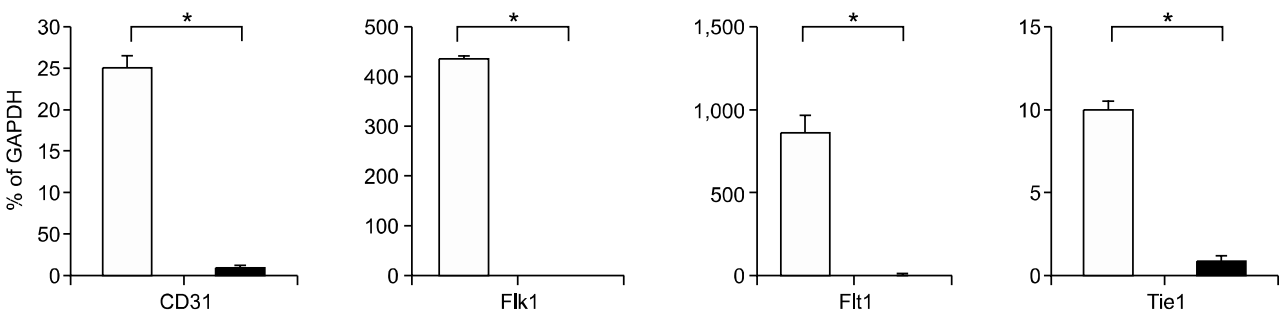

AH-SP-Cells BM-SP-Cells

Figure 2. Relative expression of marker genes, for different cell lineage commitment in adult heart- and bone marrow-SP cells. (A) RT-PCR analysis of AH- and BM-SP cells for expression of early cardiac transcription factors (GATA4, ANF and Nkx2.5). (B) Real-time PCR analysis of ABCG2, SDF1 and CXCR4 mRNAs in AH- and BM-SP cells. (C) Real-time PCR analysis of AH- and BM-SP cells for expression of endothelial cell markers (CD31, Flk1, Flt1, Tie1 and Tie2). Relative expressions of the genes $(B, C)$ analyzed through real-time PCR were normalized to that of GAPDH for each sample. Error bars indicate the SEM. ${ }^{*} P<0.05$. AH, adult heart; BM, bone marrow; SP, side population.

tic lineages; however, the hematopoietic potential of AH-SP cells was much lower than for the BM-SP cells.

\section{Adult heart SP cells differentiate into endothelial cells}

To examine the differentiation potential of AH-SP cells, into endothelial cell lineages, we cultured the cells in conditions similar to those previously reported (Reyes et al., 2001) in the presence or absence of VEGF for 28 days, and evaluated their endothelial differentiation by immunohistochemical analysis and real-time PCR. After treatment with VEGF for 28 days, AH-SP cells demonstrated morphological change and differentiated into endothelial cells which were positively stained with anti-CD31 and anti-vWF antibodies (Figure 4A).

To further investigate endothelial differentiation of $\mathrm{AH}-\mathrm{SP}$ cells under these conditions, expression of Angiopoietin1, Angiopoietin2, CD31 and VEGF was assessed by RT-PCR or quantitative real-time PCR. Expression of Angiopoietin1 and Angiopoietin2 which were known to be important factors for vascular maturation and stability during angiogenic process was detected in only VEGF-treated AH-SP cells compared to the control groups (Figure 4B). Real-time PCR showed that CD31 and VEGF mRNA were expressed $\sim 3.0$ - and $\sim 4.2$-fold in VEGF-treated AH-SP cells compared to the control groups (Figure 4B). These results demonstrate that AH-SP cells have intrinsic potential for differentiating into an endothelial cell lineage in response to angiogenic stimulatory growth factors such as VEGF.

\section{Adult heart-SP cells transplanted into ischemic hindlimb restored blood flow}

To investigate the endothelial potential, of $\mathrm{AH}-\mathrm{SP}$ cells in vivo, we performed transplantation of AH-SP cells to the ischemic hindlimb. Left limb ischemia was created in 30 animals, and AH-SP cells isolated on day 1 after surgery were locally transplanted into the ischemic thigh muscle area $\left(1 \sim 2 \times 10^{5} \mathrm{AH}-\mathrm{SP}\right.$ cells/mouse $)$ at four different injection points. Serial analyses revealed a signi- 

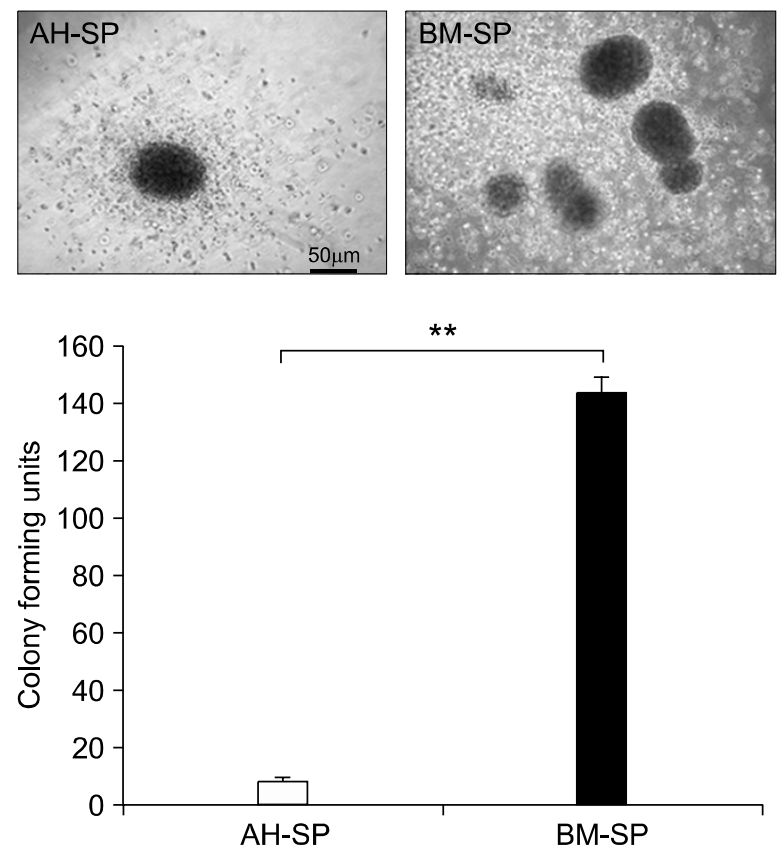

Figure 3. Hematopoietic colony forming assay. Four $\times 10^{3} \mathrm{SP}$ cells prepared from bone marrow or heart were cultured in Methocult medium for hematopoietic colony assays for 14 days. A number of hematopoietic colonies were formed in BM-SP cells $(143.6 \pm 4.9)$, whereas AH-SP cells only gave rise to less than 10 colonies $(9 \pm 1.1)$. Values (mean \pm $\mathrm{SEM}$ ) are based on five separate experiments. ${ }^{* *} \mathrm{P}<0.01$. AH, adult heart; BM, bone marrow; SP, side population.

ficantly augmented ratio of ischemic/normal hindlimb blood flow in the AH-SP cell-transplanted group compared with the saline-treated controls on postoperative days: 7, 14, 21 and 28 (Figure 5A and $5 \mathrm{~B}$ ). Over the subsequent 28 days, substantial blood flow recovery, in mice receiving AH-SP cells, was observed. We observed returned perfusion of the ischemic hindlimb to levels that were similar to those recorded in the contralateral nonischemic hindlimb. Enhanced neovasculogenesis in mice undergoing transplantation with $\mathrm{AH}-\mathrm{SP}$ cells led to important biological consequences. Most mice injected with saline typically had extensive limb necrosis, leading to autoamputation of the ischemic limb. By contrast, among mice receiving $\mathrm{AH}-\mathrm{SP}$ cells, limb salvage occurred in 10 of 30 animals and tip necrosis occurred 9 of 30 animals. The difference in outcome, between the heartderived SP cells and the control group, was statistically significant. Dil-labeled AH-SP cells were detected in the ischemic area of the hindlimb at 4 weeks after transplantation (Figure 5C). Most AH-SP cells did not express vWF or $\alpha-S M A$, but the transplanted AH-SP cells were survived in the ischemic region of hindlimb until 4 weeks (Figure 5C). Only a small portion of Dil-labeled AH-SP
A
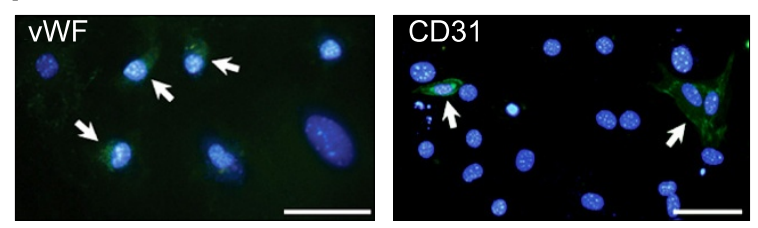

B

C
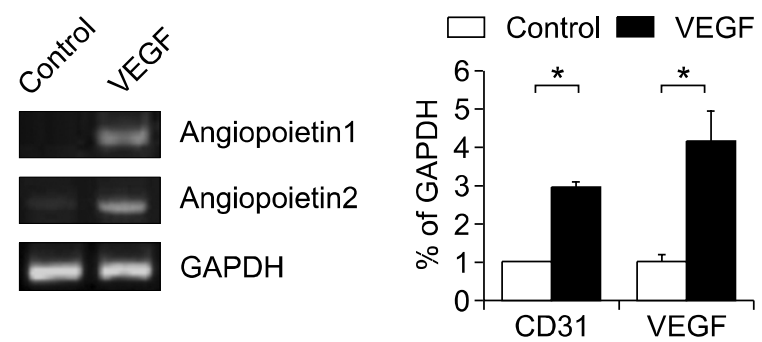

Figure 4. Endothelial differentiation of adult heart-SP cells. (A) The cells were cultured in the presence of VEGF for 28 days and then immunostained with anti-vWF and anti-CD31 antibodies. Representative immunofluorescence microscopy images were shown. Arrows indicate VWF- and CD31-positive signals. Scale bars $=50 \mu \mathrm{m}$. (B) Endothelial differentiation of AH-SP cells was assessed by RT-PCR or real-time PCR with Angiopoietin1, Angiopoietin2, CD31 and VEGF primers. The relative expression levels of CD31 and VEGF mRNA were quantified based on the threshold cycle $(\mathrm{Ct})$, and normalized to the reference gene GAPDH. Error bars indicate the SEM. ${ }^{*} P<0.05$. AH, adult heart; SP, side population.

cells expressed VWF, an endothelial marker, and were positive for $\alpha$-SMA, a marker of vascular smooth muscle cells as indicated by arrows (Figure 5C). To investigate quantitative expression of molecules involved in the formation of new capillary blood vessels in AH-SP cell transplanted regions, expression of Flk1 and VWF was assessed by real-time PCR. Flk1 ( $1 \pm 0.13$-fold vs. $1.43 \pm$ 0.12 -fold) and vWF mRNA expression levels ( $1 \pm$ 0.14 -fold vs. $1.61 \pm 0.27$-fold) in AH-SP cell transplanted group compared to the control group were significantly increased (Figure 5D).

\section{Discussion}

In the present study, cardiac SP cells were enriched for Sca1 ( 92\%) but demonstrated relatively low numbers of CD45 within their SP compartments by comparison to the BM-SP cells. Similarly, Oh et al. (2003) reported that cardiac SP cells are $>93 \% \mathrm{Sca}^{+}$, differ from bone marrow SP cells by typically lacking CD45 and c-kit. Sca- $1^{+}$ cardiac cells also showed stem cell properties differentiating into cardiac and endothelial cells in vitro and in vivo (Oh et al., 2003; Matsuuura et al., 
A

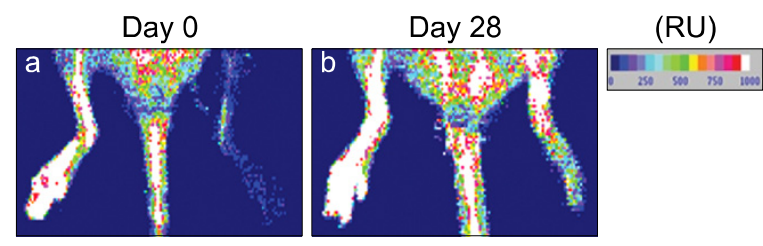

B

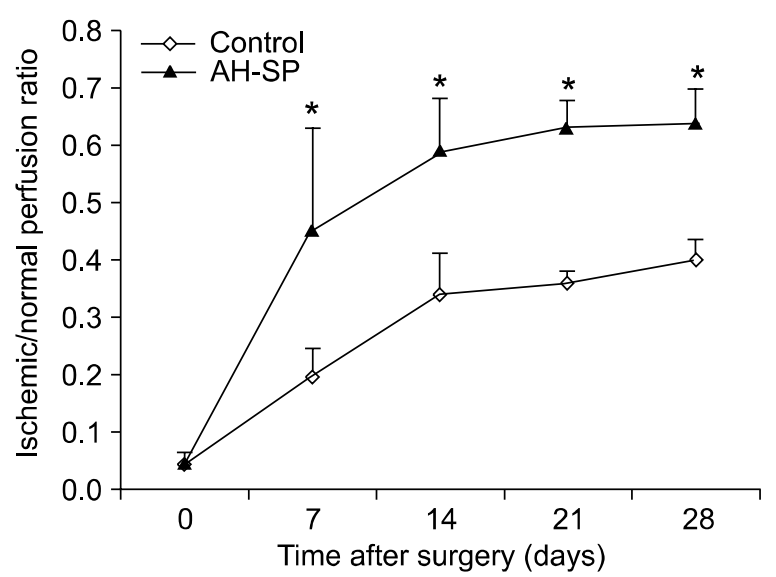

C
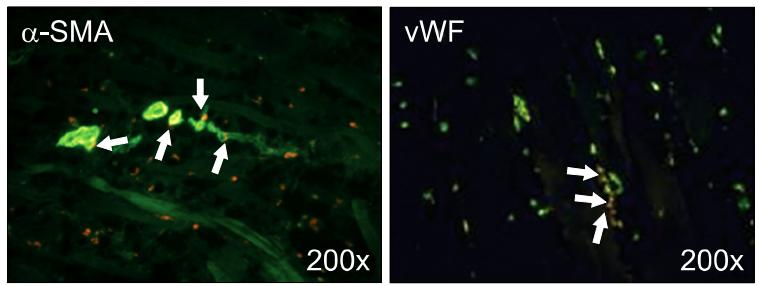

D

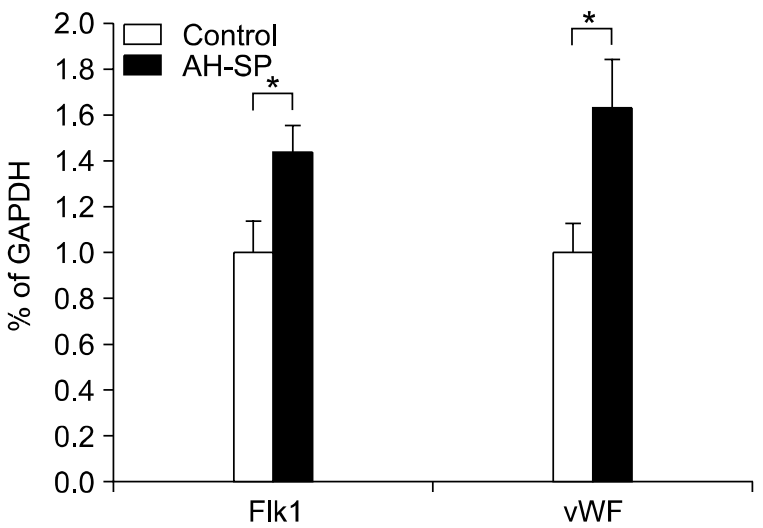

Figure 5. LDPI analyses of hindlimb blood perfusion after transplantation of adult heart-SP cells into the ischemic hindlimb (A) Improved blood perfusion on day 28 after induction of hindlimb ischemia was observed in AH-SP group. RU indicates relative units. (B) Blood perfusion ratio after induction of limb ischemia was significantly higher in the AH-SP group than in controls on postoperative days 7, 14, 21 and 28, respectively. Values are mean \pm SEM ( $n=$ 30). ${ }^{*} P<0.05$. AH, adult heart; SP, side population. (C) Incorporation and endothelial differentiation of AH-SP cells in vivo. Red fluorescence marks transplanted Dil-labeled AH-SP cells whereas green fluorescence indicates an endothelial cell marker, vWF or a marker of vascular smooth muscle cells, $\alpha$-SMA. Arrows indicate Dil-labeled/vWF-double positive cells or Dil-labeled/ $\alpha$-SMA-double positive cells. $\alpha$-SMA, $\alpha$-smooth muscle actin; vWF, von Willebrand Factor. (D) Real-time PCR analysis of Flk1 and vWF mRNA transcripts in the lower hindlimb musculatures after transplantation of adult heart-SP cells into the ischemic hindlimb. The relative expression levels of Flk1 and vWF mRNA were quantified based on the threshold cycle (Ct), and normalized to the reference gene GAPDH. Error bars indicate the SEM. ${ }^{*} P<0.05$. AH, adult heart; SP, side population; vWF, von Willebrand Factor.

2004; Wang et al., 2006). These results suggest that Sca1 might be a common marker for cardiac progenitor cells. In AH-SP cells, c-kit was expressed on a proportion of about $9.6 \%$ SP cells whereas about $30 \%$ BM-SP cells expressed c-kit. Cardiac SP cells are c-kit ${ }^{\text {low }}, \mathrm{CD} 34^{\text {low }}$, and CD $45^{\text {low }}$, and are distinct from the differentiated endothelial cells within the heart (Pfister et al., 2005). In contrast, lin-/c-kit ${ }^{+}$cardiac cells were self-renewing, clonogenic, and multipotent, giving rise to myocytes, smooth muscle, and endothelial cells (Beltrami et al., 2003). Previous studies demonstrated hematopoietic stem cells could be isolated from various tissues such as bone marrow, peripheral blood and cord blood, these cells represented high c-kit expression (Balsam et al., 2004; Nygren et al., 2004; Wojakowski et al., 2004; Chung et al., 2005; Noh et al., 2005). We also observed that early cardiac transcription factors such as Nkx2.5, GATA4 and ANF were expressed only in AH-SP cells but were not detectable in
BM-SP cells under our experimental conditions. These results suggest that AH-SP cells demonstrate a greater intrinsic potential for cardiomyogenic differentiation than BM-SP cells. Similarly, Pfister et al. (2005) reported that cardiac Sca $1^{+} / \mathrm{SP}$ cells expressed early cardiac transcription factors and contractile proteins which play a pivotal role in cardiomyogenesis and cardiac development, but no cardiac Sca1 ${ }^{-}$/SP cells. These results suggest that BM-SP cells represent hematopoietic stem cell-like phenotypic characterization whereas $\mathrm{AH}-$ SP cells resemble the myogenic cells in skeletal muscle that are Sca- $1^{+}$but $\mathrm{CD}_{4} 5^{-}$and $\mathrm{c}$-kit (McKinney-Freeman et al., 2002).

Nygren et al. (2004) reported that BM-derived hematopoietic stem cells generate cardiomyocytes at a low frequency through cell fusion, but not transdifferentiation. In another study, c-kit-enriched BM cells, Lin $^{-} \mathrm{C}-\mathrm{kit}^{+} \mathrm{BM}$ cells and c-kit ${ }^{+}$Thy $1.1^{\mathrm{lo}} \mathrm{Lin}^{-}$ Sca $1^{+}$hematopoietic stem cells adopt only traditional hematopoietic differentiation (Balsam et al., 
2004). On the basis of these reports, we expected that BM-SP cells would express more endothelial or hematopoietic stem cell markers than AH-SP cells. However, endothelial cell markers such as CD31, Flk1, Flt1, Tie1 and Tie2 genes relative to $\mathrm{BM}-\mathrm{SP}$ were more highly expressed in $\mathrm{AH}-\mathrm{SP}$ cells than BM-SP cells. Furthermore, AH-SP cells represented morphological change as well as differentiated into VWF-positive endothelial cells after being treated with VEGF in vitro. However, BM-SP cells did not show any morphological change in the endothelial differentiation medium containing VEGF (data not shown). Based on our observations, we speculate that AH-SP cells may indeed represent early endothelial progenitors, suggesting that they may participate in vascular regeneration of injured myocardium. In accordance with our results, Martin et al. (2004) also reported that a number of transcripts expressed in endothelial or hematopoietic cells were more highly enriched in cardiac SP cells than in embryonic stem cells or adult cardiomyocytes through microarray analysis experiment.

SDF1/CXCR4 molecules are known to mediate trafficking and homing of stem cells in the bone marrow after induction of a myocardial infarction (Yong et al., 1999; Askari et al., 2003). In this study, we found that BM-SP cells expressed high levels of CXCR4 relative to AH-SP cells whereas SDF1 was highly expressed in AH-SP cells compared to the BM-SP cells. Based on these results, we speculate that $\mathrm{AH}-\mathrm{SP}$ cells, expressing high levels of SDF1, may participate in stem-cell mobilization into infarcted myocardium. In addition, BM-SP cells, expressing high levels of CXCR4, could efficiently mobilize into various damaged tissues responding to chemokines and participate in the regeneration process of injured tissues.

SP cells with enriched hematopoietic ability were first isolated from mouse bone marrow by their intrinsic capacity to efflux Hoechst dye (Goodell et al., 1996). In the present study, we observed that the cardiac SP cells gave rise to a lower frequency of hematopoietic colonies compared with those of bone marrow. Similarly, Pfister et al. (2005) also reported a greater colony forming activity in cardiac $\mathrm{SP}$ cells relative to the main population of cells that were observed. However, arterial SP cells that displayed a Sca ${ }^{+} \mathrm{c}-\mathrm{kit}^{-(- \text {low })} \mathrm{Lin}^{-} \mathrm{CD} 34^{(- \text {llow })}$ profile did not form myeloid or lymphoid hematopoietic colonies after plating in methylcellulose-based medium (Sainz et al., 2006). Therefore, these results indicate that cardiac SP cells possess hematopoietic colony forming activity capable of differentiating into the myeloid lineage or the lymphoid lineage; however, their hematopoietic activity was relatively lower than that of the BM-SP cells.

In this study, we found that only small number of AH-SP cells coexpressed VWF or $\alpha$-SMA at 4 weeks after transplantation whereas most AH-SP cells remained without differentiation into endothelial or vascular smooth muscle cell lineage. Nevertheless, the blood flow in the AH-SP cell transplanted group was significantly improved compared to controls. Restoration of blood flow in the AH-SP cell transplanted group might be caused by releasing a variety of cytokines and factors capable of paracrine signaling from the transplanted cells rather than direct differentiation into vascular smooth muscle cell or vascular endothelial cells because the transplanted AH-SP cells still survived in the ischemic region of hindlimb at 4 weeks after transplantation. Similar to our observation, despite the cardiac improvement, there was no evident human mesenchymal stem cell engraftment in the heart 3 weeks after myocardial infarction, indicating that the favorable effects of factors secreted in the transplanted cells rather than engraftment, differentiation, or cell fusion (Iso et al., 2007). However, direct differentiation into endothelial cell lineage of the transplanted AH-SP cells might also contribute to the improvement of blood flow. Oyama et al. (2007) recently showed that cardiac SP cells in injured heart differentiated into cardiomyocytes, endothelial cells, or smooth muscle cells $(4.4 \%, 6.7 \%$, and $29 \%$ of total cardiac SP-derived cells), suggesting that cardiac SP cells may be intrinsic cardiac stem cells and involved in the regeneration of diseased hearts.

In conclusion, we found that cardiac SP cells intrinsically express early cardiac transcription factors as well as endothelial cell markers. Furthermore, we demonstrated that cardiac SP cells could transdifferentiate into endothelial cells in vitro as well as restore blood flow after transplantation into the ischemic hindlimb of mice in vivo. Our observations suggest that cardiac SP cells may function as a cardiac progenitor cell population with the potential to transdifferentiate into endothelial as well as myogenic lineages.

\section{Acknowledgments}

This work was supported by a grant (SC3170) from the Stem Cell Research Center of the 21st Century Frontier Research Program, which is funded by the Ministry of Science and Technology, and by a grant of Seoul R\&BD Program. 


\section{References}

Asakura A, Rudnicki MA. Side population cells from diverse adult tissues are capable of in vitro hematipoietic differentiation. Exp Hematol 2002;30:1339-45

Askari AT, Unzek S, Popovic ZB, Goldman CK, Forudi F, Kiedrowski M, Rovner A, Ellis SG, Thomas JD, DiCorleto PE, Topol EJ, Penn MS. Effect of stromal-cell-derived factor 1 on stem cell homing and tissue regeneration in ischaemic cardiomyopathy. Lancet 2003;362:697-703

Balsam LB, Wagers AJ, Christensen JL, Kofidis T, Weissman IL, Robbins RC. Haematopoietic stem cells adopt mature haematopoietic fates in ischaemic myocardium. Nature 2004;428:668-73

Beltrami AP, Urbanek K, Kajstura J, Yan SM, Finato N, Bussani R, Nadal-Ginard B, Silvestri F, Leri A, Beltrami CA, Anversa P. Evidence that human cardiac myocytes divide after myocardial infarction. N Engl J Med 2001;344:1750-7

Beltrami AP, Barlucchi L, Torella D, Baker M, Limana F, Chimenti S, Kasahara H, Rota M, Musso E, Urbanek K, Leri A, Kajstura J, Nadal-Ginard B, Anversa P. Adult cardiac stem cells are multipotent and support myocardial regeneration. Cell 2003;114:763-6

Choi SC, Yoon J, Shim WJ, Ro YM, Lim DS. 5-azacytidine induces cardiac differentiation of P19 embryonic stem cells. Exp Mol Med 2004;36:515-23

Chung JW, Kim GY, Mun YC, Ahn JY, Seong CM, Kim JH. Leukotriene B4 pathway regulates the fate of the hematopoietic stem cells. Exp Mol Med 2005;37:45-50

Goodell MA, Brose K, Paradis G, Conner AS, Mulligan RC. Isolation and functional properties of murine hematopoietic stem cells that are replicating in vivo. J Exp Med 1996; 183:1797-806

Hierlihy AM, Seale P, Lobe CG, Rudnicki MA, Megeney LA The post-natal heart contains a myocardial stem cell population. FEBS Lett 2002;530:239-43

Iso Y, Spees JL, Serrano C, Bakondi B, Pochampally R, Song $\mathrm{YH}$, Sobel BE, Delafontaine P, Prockop DJ. Multipotent human stromal cells improve cardiac function after myocardial infarction in mice without long-term engraftment. Biochem Biophys Res Commun 2007;354:700-6

Lassalle B, Bastos H, Louis JP, Riou L, Testart J, Dutrillaux B, Fouchet P, Allemand I. 'Side Population' cells in adult mouse testis express Bcrp1 gene and are enriched in spermatogonia and germinal stem cells. Development 2004;131:479-87

Laugwitz KL, Moretti A, Lam J, Gruber P, Chen Y, Woodard S, Lin LZ, Cai CL, Lu MM, Reth M, Platoshyn O, Yuan JX, Evans S, Chien KR. Postnatal is $11^{+}$cardioblasts enter fully differentiated cardiomyocyte lineages. Nature 2005;433: 647-53

Martin CM, Meeson AP, Robertson SM, Hawke TJ, Richardson JA, Bates S, Goetsch SC, Gallardo TD, Garry DJ. Persistent expression of the ATP-binding cassette transporter, Abcg2, identifies cardiac SP cells in the developing and adult heart. Dev Biol 2004;265:262-75
Matsuura K, Nagai T, Nishigaki N, Oyama T, Nishi J, Wada $\mathrm{H}$, Sano M, Toko H, Akazawa H, Sato T, Nakaya H, Kasanuki $\mathrm{H}$, Komuro I. Adult cardiac Sca-1-positive cells differentiate into beating cardiomyocytes. J Biol Chem 2004;279:1138491

McKinney-Freeman SL, Jackson KA, Camargo FD, Ferrari G, Mavilio F, Goodell MA. Muscle-derived hematopoietic stem cells are hematopoietic in origin. Proc Natl Acad Sci USA 2002;99:1341-6

Noh EK, Ra JS, Lee SA, Kwon BS, Han IS. CKbeta8-1 alters expression of cyclin $E$ in colony forming units-granulocyte macrophage (CFU-GM) lineage from human cord blood CD34+ cells. Exp Mol Med 2005;37:619-23

Nygren JM, Jovinge S, Breitbach M, Sawen P, Roll W, Hescheler J, Taneera J, Fleischmann BK, Jacobsen SE. Bone marrow-derived hematopoietic cells generate cardiomyocytes at a low frequency through cell fusion, but not transdifferentiation. Nat Med 2004;10:494-501

Oh H, Bradfute SB, Gallardo TD, Nakamura T, Gaussin V, Mishina Y, Pocius J, Michael LH, Behringer RR, Garry DJ, Entman ML, Schneider MD. Cardiac progenitor cells from adult myocardium: homing, differentiation, and fusion after infarction. Proc Natl Acad Sci USA 2003;100:12313-8

Oyama T, Nagai T, Wada H, Naito AT, Matsuura K, Iwanaga K, Takahashi T, Goto M, Mikami Y, Yasuda N, Akazawa H, Uezumi A, Takeda S, Komuro I. Cardiac side population cells have a potential to migrate and differentiate into cardiomyocytes in vitro and in vivo. J Cell Biol 2007;176:329-41

Pfister O, Mouquet F, Jain M, Summer R, Helmes M, Fine A Colucci WS, Liao R. CD $31^{-}$but Not $\mathrm{CD} 31^{+}$cardiac side population cells exhibit functional cardiomyogenic differentiation. Circ Res 2005;97:52-61

Reyes M, Lund T, Lenvik T, Aguiar D, Koodie L, Verfaillie CM Purification and ex vivo expansion of post-natal human marrow mesodermal progenitor cells. Blood 2001;98:261525

Sainz J, Al Haj Zen A, Caligiuri G, Demerens C, Urbain D, Lemitre M, Lafont A. Isolation of "side population" progenitor cells from healthy arteries of adult mice. Arterioscler Thromb Vasc Biol 2006;26:281-6

Wang X, Hu Q, Nakamura Y, Lee J, Zhang G, From AH, Zhang $\mathrm{J}$. The role of the sca-1+/CD31- cardiac progenitor cell population in postinfarction left ventricular remodeling. Stem Cells 2006;24:1779-88

Welm BE, Tepera SB, Venezia T, Graubert TA, Rosen JM, Goodell MA. Sca-1(pos) cells in the mouse mammary gland represent an enriched progenitor cell population. Dev Biol 2002;245:42-56

Wojakowski W, Tendera M, Michalowska A, Majka M, Kucia M, Maslankiewicz K, Wyderka R, Ochala A, Ratajczak MZ. Mobilization of CD34/CXCR4+, CD34/CD117+, c-met+ stem cells, and mononuclear cells expressing early cardiac, muscle, and endothelial markers into peripheral blood in patients with acute myocardial infarction. Circulation 2004;110:3213-20

Yano S, Ito Y, Fujimoto M, Hamazaki TS, Tamaki K, Okochi 
662 Exp. Mol. Med. Vol. 39(5), 653-662, 2007

H. Characterization and localization of side population cells in mouse skin. Stem Cells 2005;23:834-41

Yong K, Fahey A, Reeve L, Nicholls C, Thomas NS, Pizzey

A. Cord blood progenitor cells have greater transendothelial migratory activity and increased responses to SDF-1 and MIP-3 beta compared with mobilized adult progenitor cells. Br J Haematol 1999;107:441-9 